\title{
Desigualdade de gênero nos estados brasileiros e análise dos stakeholders do Conselho Nacional dos Direitos da Mulher
}

\author{
Gabriel Oliveira Loiola Benigno ${ }^{1}$ \\ Diego Mota Vieira 1 \\ Jessica Eloísa de Oliveira 1 \\ 1 Universidade de Brasília / Programa de Pós-Graduação em Administração, Brasilia / DF - Brasil
}

O objetivo deste artigo é analisar a desigualdade entre homens e mulheres nas unidades federativas brasileiras e a atuação dos stakeholders do Conselho Nacional dos Direitos da Mulher (CNDM). Para tal, realizaram-se duas etapas de pesquisa. A primeira é baseada no cálculo de um índice sobre a disparidade entre gêneros nos estados brasileiros a partir da metodologia aplicada no Global Gender Gap Report (GGGR), elaborado pelo Fórum Econômico Mundial. Na segunda, foram mapeados os stakeholders do CNDM e analisada sua atuação diante das lacunas enfatizadas na primeira fase do estudo, à luz de referencial teórico amparado em modelos de análise de stakeholders. No Brasil, as dimensões que apresentaram o pior desempenho foram a política e a econômica, sendo as unidades federativas que obtiveram os melhores índices gerais Amapá, Distrito Federal e Maranhão, e os piores, Mato Grosso, Minas Gerais e Paraná. Por outro lado, os stakeholders do CNDM que atuam nas políticas públicas ligadas às dimensões econômica e política parecem não ter grande relevância e capacidade de influência. As evidências indicam que existe concentração de esforços em políticas nas áreas em que o país apresenta bons indicadores no GGGR, como saúde e educação.

Palavras-chave: gênero; desigualdade; políticas públicas; stakeholders; representatividade política.

\section{Desigualdad de género en los estados brasileños y análisis de stakeholders del Consejo Nacional para los Derechos de la Mujer}

El objetivo de este artículo es analizar la brecha de género en las unidades federativas brasileñas y las acciones de los stakeholders del Consejo Nacional para los Derechos de la Mujer (CNDM). Con este fin, se realizaron dos etapas de investigación. La primera se basa en el cálculo de un índice sobre la brecha de género en los estados brasileños a partir de la metodología aplicada en el Global Gender Gap Report (GGGR), preparado por el Foro Económico Mundial. En la segunda etapa, se mapeareon los stakeholders del CNDM y se analizó su desempeño en vista de las brechas destacadas en la primera fase del estudio, a la luz del marco teórico respaldado por los modelos de análisis de stakeholders. En Brasil, las dimensiones de peor desempeño fueron la política y la económica, las unidades federativas que obtuvieron los mejores índices generales fueron Amapá, Distrito Federal y Maranhão, y las peores fueron Mato Grosso, Minas Gerais y Paraná. Por otro lado, los stakeholders del CNDM que actúan en políticas públicas relacionadas con las dimensiones económica y política no parecen tener gran relevancia e influencia. La evidencia indica que hay una concentración de esfuerzos en políticas en áreas donde el país tiene buenos indicadores de GGGR (salud y educación). Palabras clave: género; desigualdad; políticas públicas; stakeholders; representatividad política.

\section{Gender gap in Brazilian states and stakeholder analysis of the National Council for Women's Rights}

This paper aims to analyze the gender gap in Brazilian states and the actions of stakeholders of the National Council for Women's Rights (NCWR). Two research was conducted in two steps. In the first step, a gender gap index in Brazilian states was calculated based on the Global Gender Gap Report (GGGR) methodology, prepared by the World Economic Forum. In the second, the NCWR stakeholders were mapped, and their performance was analyzed, considering the gender gap indexes obtained in the first step and the theoretical framework supported by stakeholder analysis models. The political and economic dimensions presented the worst performance. The Brazilian states with the best general indexes were Amapá, Distrito Federal, and Maranhão, and the worst were Mato Grosso, Minas Gerais, and Paraná. On the other hand, NCWR stakeholders acting in public policies related to the economic and political dimensions do not seem to have great relevance and influence capacity. Evidence indicates a concentration of policy efforts in areas where the country has good GGGR indicators (health and education). Keywords: gender; inequality; public policies; stakeholder; political representativeness. 


\section{INTRODUÇÃO}

A lacuna de gênero pode ser entendida como qualquer diferença ou como o conjunto de diferenças entre mulheres e homens no que se refere às suas atuações na sociedade, sendo que diferentes entendimentos desse tema podem ser encontrados na literatura.

Diversos índices internacionais buscam medir a disparidade de gênero por meio de uma série de indicadores. O Gender Inequality Index (GII), elaborado pelo Programa das Nações Unidas para o Desenvolvimento (Pnud), utiliza indicadores relacionados a saúde reprodutiva, empoderamento (político e educacional) e condição econômica. O Gender Development Index (GDI), também elaborado pelas Nações Unidas, mede a desigualdade de gênero por meio de três dimensões: saúde, conhecimento e padrão de vida (United Nations Development Programme, 2019). O Global Gender Gap Report (GGGR), por sua vez, trata a lacuna entre os gêneros como o conjunto de diferenças atrelado a questões de saúde, educação, economia e política (World Economic Forum [WEF], 2018). Nota-se que há semelhanças no tocante às dimensões consideradas no cálculo de índices internacionais de lacuna de gênero.

O GGGR é publicado anualmente, desde 2006, pelo Fórum Econômico Mundial (WEF, na sigla em inglês) e analisa a paridade de gênero nos países por meio de quatro dimensões: participação econômica e oportunidade, participação escolar, saúde e sobrevivência, empoderamento político. $\mathrm{Na}$ edição de 2018 do GGGR, o Brasil ficou na 95a colocação no ranking de paridade de gênero, entre 149 países classificados. Na América do Sul, o Brasil ocupa a penúltima colocação entre os 11 países classificados no GGGR, ficando na frente apenas do Paraguai, 104 colocado global. Apesar de o Brasil estar bem colocado nas dimensões de participação escolar, saúde e sobrevivência, nas outras duas dimensões o desempenho foi inferior à média global.

A dimensão "participação econômica e oportunidade" considera variáveis relacionadas à participação feminina no mercado de trabalho e à igualdade salarial. Nessa dimensão, o Brasil ocupou a 92a posição em 2018. Dados do Instituto Brasileiro de Geografia e Estatística (IBGE, 2018) sobre estatísticas de gênero mostram que o rendimento médio das mulheres naquele ano foi de $\mathrm{R} \$ 1.764,00$, enquanto a renda média dos homens foi de $\mathrm{R} \$ 2.306,00$ no mesmo período, ou seja, uma diferença de aproximadamente $23,5 \%$ em favor do sexo masculino. Outro dado que ajuda a entender a posição do Brasil nessa dimensão é que apenas 39,1\% dos cargos gerenciais eram ocupados por mulheres, o que, em conjunto com os dados sobre rendimento médio, indica uma lacuna entre os gêneros.

Na dimensão "empoderamento político" do GGGR, o Brasil teve o pior desempenho, ficando na $112^{\text {a }}$ colocação. Essa dimensão considera a diferença entre a quantidade de homens e mulheres que ocupam cargos importantes na política. No ranking global de mulheres em legislativos nacionais da Inter-Parliamentary Union (2019), o Brasil ocupa a 134ª colocação entre 192 países, resultado obtido em virtude da baixa representatividade das mulheres no Legislativo nacional. Dos 513 deputados federais eleitos em 2018, apenas 77 eram mulheres (15\%), e dos 81 senadores em exercício, só 12 eram do sexo feminino (14,8\%). Considerando que as mulheres representam $51,03 \%$ da população brasileira, segundo o censo realizado pelo IBGE em 2010, esses dados revelam que o país está distante de ter uma representação política igualitária entre os sexos.

Em busca de atenuar as diferenças entre gêneros no Brasil, o governo instituiu, em 2003, a Secretaria Nacional de Políticas para Mulheres (SPM), órgão responsável pela coordenação 
das políticas nacionais de igualdade de gênero. A principal ferramenta utilizada pela SPM para diminuir a lacuna entre os gêneros é o Plano Nacional de Políticas para as Mulheres (PNPM), cuja última edição foi lançada em 2013 e vigorou até 2015. Anteriormente à SPM, em 1985, foi criado o Conselho Nacional dos Direitos da Mulher (CNDM), pela Lei no 7.353, de 29 de agosto, primeiro órgão de caráter nacional a ter a incumbência de promover políticas públicas voltadas à eliminação da discriminação contra a mulher e atual integrante da SPM. Essas instituições articulam um diálogo entre governos federal, estaduais, municipais e a sociedade civil. No Comitê de Articulação e Monitoramento do PNPM, por exemplo, participam setores governamentais em nível federal - como ministérios, Secretaria Geral da Casa Civil, Instituto de Pesquisa Econômica e Aplicada (Ipea) e Fundação Nacional do Índio (Funai) -, além de representantes de movimentos sociais e de mecanismos governamentais de políticas estaduais e municipais para as mulheres. Observa-se que, já no PNPM I, era prevista uma rede de ações e serviços para ampliar a capacidade estatal nos estados e nos municípios, conferindo à política o status de transversalidade com abrangência nos três níveis de governo.

Diante do cenário apresentado e da limitada literatura sobre a questão de gênero e políticas públicas no Brasil em comparação com os estudos realizados em países desenvolvidos (Anglade, Useche \& Deere, 2017; Desposato \& Norrander, 2008; Rad, Bayazidi, Delavari \& Rezaei, 2016), este trabalho busca analisar a desigualdade entre homens e mulheres nas unidades federativas brasileiras e a atuação do CNDM com enfoque em seus stakeholders, definidos por Freeman (1984) como atores que influenciam ou são influenciados por uma organização. Para tal, a pesquisa foi realizada em duas etapas. A primeira consiste na elaboração de um ranking da lacuna entre gêneros dos estados brasileiros nos moldes do GGGR. A segunda etapa busca complementar a primeira por meio da identificação e da caracterização dos stakeholders do CNDM e suas atuações diante das dimensões do ranking. Afinal, acredita-se que um olhar mais detalhado, que investiga os atores interessados, sobre a realidade dos estados e a atuação da entidade responsável pelas políticas públicas nacionais dedicadas ao tema possa contribuir para uma melhor compreensão a respeito da classificação do Brasil no GGGR e fornecer evidências para um adequado prognóstico.

Analisar a desigualdade de gênero no Brasil em dois níveis (nacional e estadual) permite um estudo mais abrangente da realidade do país. O ranking de paridade de gênero nas unidades federativas brasileiras fornece uma visão das especificidades locais, enquanto a análise dos stakeholders do CNDM foca na arena responsável pela elaboração das políticas nacionais que devem pautar a atuação dos governos estaduais e municipais. Considerando que as diretrizes nacionais da política de gênero estabelecidas pela CNDM - entre as quais garantir a alocação e a execução de recursos em Planos Plurianuais, Leis de Diretrizes Orçamentárias e Leis Orçamentárias Anuais para a implementação de políticas para mulheres - devem ser seguidas pelas unidades federativas, o ranking estadual pode lançar luz sobre o alcance das políticas nacionais de disparidade de gênero.

Para cumprir os objetivos propostos, além desta seção introdutória, este trabalho contém duas seções dedicadas ao referencial teórico, uma seção sobre os métodos de pesquisa empregados, outra para resultados e discussão e, finalmente, uma destinada às conclusões, na qual também se apontam sugestões para estudos futuros. 


\section{ATUAÇÃO DA SECRETARIA NACIONAL DE POLÍTICAS PARA AS MULHERES E DO CONSELHO NACIONAL DE DIREITOS DA MULHER}

Embora muito ainda deva ser feito para que haja paridade entre homens e mulheres na sociedade brasileira, não é de hoje que a questão de gênero tem sido considerada pela esfera pública federal. Em 1985, a Lei no 7.353, de 29 de agosto, criou o CNDM, o primeiro órgão de caráter nacional a ter a incumbência de promover políticas públicas voltadas à eliminação da discriminação contra a mulher. Na época, o conselho era vinculado ao Ministério da Justiça, mas gozava de autonomia financeira e administrativa, o que lhe conferia mais liberdade para atuar em prol da igualdade de gênero. Entretanto, a força do CNDM diminuiu ao longo do tempo com alterações no cenário político e a troca de partidos na presidência (Macaulay, 2010).

Em 2002, no final do segundo mandato de Fernando Henrique Cardoso, foi criada a Secretaria de Estado dos Direitos da Mulher (Sedim), por meio da Lei no 10.539, de 23 de setembro, com o intuito de elaborar e colocar em prática as reformas políticas necessárias a uma maior paridade entre homens e mulheres no país. A Sedim foi criada com caráter especial e não modificava a realidade do CNDM. Tal modificação aconteceu no início do governo do Partido dos Trabalhadores (PT), em 2003, quando a Lei no 10.683 criou a SPM, que substituiu a Sedim e passou a ter como parte de sua estrutura básica o CNDM, agora como órgão consultivo.

O primeiro PNPM, publicado em 2004, surgiu como a principal ferramenta da SPM para diminuir a lacuna entre os gêneros no Brasil. Seu escopo tem uma série de recomendações e normas que buscam assegurar que os direitos das mulheres sejam respeitados. O PNPM conta com três edições, tendo a última sido publicada em 2013.

Com o governo Dilma Rousseff, iniciado em 2010, a SPM passou por uma série de modificações que visavam sua melhoria, mas também foi nesse período que a secretaria sofreu a perda do status de ministério, o que acarretou redução de poder, abrangência e autonomia. A Medida Provisória $\mathrm{n}^{\circ}$ 696, de 2 de outubro de 2015, deu fim ao Ministério das Mulheres, integrando-o ao Ministério das Mulheres, da Igualdade Racial, da Juventude e dos Direitos Humanos (MMIRDH), junto com outras secretarias. Por sua vez, já após o impeachment de Dilma, no governo de Michel Temer, a Lei $\mathrm{n}^{\circ}$ 13.341, de 29 de setembro de 2016, extinguiu o MMIRDH e transferiu todas as suas atribuições para o Ministério da Justiça e da Cidadania, ressalvadas aquelas relacionadas a políticas para a juventude. Atualmente, no governo de Jair Bolsonaro, o CNDM está ativo e integra a estrutura do Ministério da Mulher, da Família e dos Direitos Humanos (MDH).

\section{MODELOS DE ANÁLISE DE STAKEHOLDERS}

Entender a dinâmica entre os stakeholders e como esses atores podem exercer influência sobre uma política pública pode representar a diferença entre um plano bem-sucedido e um infrutífero. Assim, vários estudos se dedicaram a encontrar maneiras de classificar esses atores, entre os quais figuram os trabalhos de Savage, Whitehead e Blair (1991), Mitchell, Agle e Wood (1997) e Gomes, Liddle e Gomes (2010).

No entendimento de Savage et al. (1991), os stakeholders podem ser classificados de acordo com seu potencial de ameaça ou de cooperação, sendo divididos em quatro grupos: supportive stakeholders, com alto potencial de cooperação e baixo de ameaça; marginal stakeholders, dotados de baixo potencial para ameaça e cooperação; nonsupportive stakeholders, com alto potencial de ameaça e baixo de cooperação; e mixed blessing stakeholders, caracterizados por alto potencial de ameaça e de cooperação. 
A proposta de Mitchell et al. (1997) leva em conta aspectos mais intrínsecos dos stakeholders, classificando-os de acordo com a presença ou a ausência de três atributos: poder exercido (coercitivo, normativo ou utilitário), legitimidade e urgência de suas demandas. Os atores com apenas um dos três atributos são chamados de "latentes" e se dividem em "dormentes", que apresentam somente poder sem de fato exercê-lo; "discricionários", detentores de legitimidade que se mantêm inertes pela falta de poder e urgência; e "demandantes", caracterizados por fazer alarde com a urgência de suas demandas. Aqueles atores com duas das três características em questão são os "expectantes" e se dividem em "dominantes", que têm poder e legitimidade e podem agir de maneira impactante; "perigosos", donos de urgência e capazes de utilizar formas de poder coercitivo para atingir seus objetivos; e "dependentes", tidos como aqueles que detêm urgência e legitimidade, mas dependem do poder de outros atores para ser ouvidos. Por fim, os stakeholders dotados de poder, legitimidade e urgência são os "definitivos", que precisam ser observados com maior cuidado, já que suas ações podem influenciar em grande medida a realidade do objeto de estudo na análise de stakeholders.

Pautados numa pesquisa relacionada a políticas públicas que teve como objeto de estudo os governos da Inglaterra e do Brasil, Gomes et al. (2010) elaboraram um modelo de análise de stakeholders que tem base na atitude dos atores frente às decisões tomadas pela política pública ou pela organização em análise. Desse modo, os stakeholders podem ser "colaboradores", que auxiliam o poder público a implementar seus planos; "reguladores", que gerenciam o capital aplicado nos planos governamentais; "desenvolvedores de agenda", responsáveis por estabelecer tópicos que devem ser seguidos, "legitimadores", que oferecem ao poder público o direito de agir em seu favor, e "controladores", capazes de limitar as ações por meios formais ou informais.

Dessa forma, propõe-se uma abordagem para a análise de stakeholders que leve em consideração, de maneira simultânea, os três modelos referenciados. Assim, é possível verificar: a atitude (positiva, negativa ou ambígua) dos atores em relação à política, o grau de relevância de cada ator interessado àquela política e o papel que cada ator exerce no subsistema político no qual a política pública opera.

\section{PROCEDIMENTOS METODOLÓGICOS}

Este estudo tem natureza quantitativa e qualitativa, pois a primeira etapa da pesquisa se baseia no cálculo de um índice sobre a lacuna de gênero nos estados brasileiros e a segunda na reunião de informações qualitativas, entrevistas e documentos do órgão federal responsável pelas políticas para mulheres: a CNDM. Dessa forma, o trabalho busca explorar e descrever a situação da paridade de gênero nas diversas unidades que integram o Brasil, tarefa mais completa ao se unir ferramentas quantitativas e qualitativas (Sampieri, Collado \& Lucio, 2006).

Para a primeira etapa, construção do índice para as unidades federativas brasileiras, buscou-se replicar a metodologia empregada pelo WEF na elaboração do GGGR 2018, que é a mesma utilizada desde o início do estudo internacional, em 2006. No entanto, como o relatório trabalha com países, foram necessários ajustes de escopo, ou seja, redução de escala do nível nacional para o estadual, de modo a considerar a realidade das unidades federativas brasileiras. Ademais, outras modificações foram necessárias, já que nem todas as variáveis utilizadas no trabalho original estavam disponíveis em nível estadual (Quadro 1). Com o cálculo do índice para os estados brasileiros e o Distrito Federal, elaborou-se um ranking referente ao nível de paridade entre os gêneros nas unidades federativas. 
O Quadro 1 elenca os quatro subíndices considerados no estudo, as variáveis utilizadas no GGGR 2018, as variáveis após a adaptação para o caso das unidades federativas brasileiras e as fontes utilizadas para a coleta dos dados. Nas variáveis dos subíndices "saúde e sobrevivência" e "grau de escolaridade", não houve mudança que não a de escopo. No subíndice "participação econômica e oportunidade", três variáveis foram ajustadas por não haver dados disponíveis relativos ao desempenho das unidades da federação. Em vez da pesquisa utilizada pelo WEF para medir a diferença salarial entre mulheres e homens dentro do mesmo cargo, utilizou-se a média salarial feminina dividida pela masculina. Outra variável que precisou ser ajustada foram os ganhos monetários femininos sobre os masculinos, que incluem rendimentos além do salário - para os estados, foi considerado o ganho salarial feminino em todos os trabalhos dividido pela contraparte masculina. Por fim, o total de mulheres em posição de empregadoras ou que trabalham por conta própria dividido pelo total de homens na mesma posição substituiu o número de mulheres legisladoras, oficiais e gerentes dividido pela contraparte masculina.

No quarto subíndice, "empoderamento político", a variável de mulheres com vagas no parlamento sobre homens parlamentares foi dividida em três novas variáveis, que representam o poder legislativo no Brasil: deputadas federais sobre deputados federais, deputadas estaduais/distritais sobre a contraparte masculina e senadoras sobre senadores. Nesse mesmo subíndice também foi incluída a variável de presença ou ausência de secretaria dedicada exclusivamente à questão de gênero, sendo atribuído o valor 1 (paridade) às unidades que apresentam secretaria dedicada, 0,5 para as unidades que apresentam uma secretaria que divide a questão de gênero com outras pautas e 0 (disparidade) para unidades que não incluem a questão de gênero em qualquer secretaria, variável baseada na importância da representatividade feminina em quadros elevados do governo (Desposato \& Norrander, 2008).

\section{QUADRO 1 VARIÁVEIS UTILIZADAS PARA O CÁLCULO DO RANKING NACIONAL E SUAS RESPECTIVAS FONTES}

\begin{tabular}{|c|c|c|c|}
\hline Subíndices & $\begin{array}{l}\text { Variável para o caso de países } \\
\text { (GGGR 2018) }\end{array}$ & $\begin{array}{c}\text { Variável para o caso de unidades } \\
\text { federativas }\end{array}$ & Fonte de dados \\
\hline \multirow{2}{*}{$\begin{array}{l}\text { Saúde e } \\
\text { Sobrevivência }\end{array}$} & Proporção de sexo no nascimento & Proporção de sexo no nascimento & $\begin{array}{l}\text { IBGE - Estatísticas de } \\
\text { registro civil } 2016\end{array}$ \\
\hline & $\begin{array}{l}\text { Proporção: expectativa de vida } \\
\text { feminina sobre a masculina }\end{array}$ & $\begin{array}{l}\text { Proporção: expectativa de vida } \\
\text { feminina sobre a masculina }\end{array}$ & $\begin{array}{l}\text { Tábua de Mortalidade } \\
\text { Completa - } 2016\end{array}$ \\
\hline \multirow{4}{*}{$\begin{array}{l}\text { Grau de } \\
\text { Escolaridade }\end{array}$} & $\begin{array}{l}\text { Proporção: alfabetização feminina } \\
\text { sobre a masculina }\end{array}$ & $\begin{array}{l}\text { Proporção: alfabetização feminina } \\
\text { sobre a masculina }\end{array}$ & Censo demográfico 2010 \\
\hline & $\begin{array}{c}\text { Proporção: matrícula feminina na } \\
\text { escola primária sobre matrícula } \\
\text { masculina }\end{array}$ & $\begin{array}{c}\text { Proporção: matrícula feminina no } \\
\text { ensino infantil sobre matrícula } \\
\text { masculina }\end{array}$ & $\begin{array}{l}\text { Sinopse estatística da } \\
\text { educação básica } 2017\end{array}$ \\
\hline & $\begin{array}{c}\text { Proporção: matrícula feminina na } \\
\text { escola secundária sobre matrícula } \\
\text { masculina }\end{array}$ & $\begin{array}{c}\text { Proporção: matrícula feminina no } \\
\text { ensino fundamental sobre matrícula } \\
\text { masculina }\end{array}$ & $\begin{array}{l}\text { Sinopse estatística da } \\
\text { educação básica } 2017\end{array}$ \\
\hline & $\begin{array}{l}\text { Proporção: matrícula feminina na } \\
\text { escola terciária sobre a masculina }\end{array}$ & $\begin{array}{c}\text { Proporção: matrícula feminina } \\
\text { no ensino médio sobre matrícula } \\
\text { masculina }\end{array}$ & $\begin{array}{l}\text { Sinopse estatística da } \\
\text { educação básica } 2017\end{array}$ \\
\hline
\end{tabular}




\begin{tabular}{|c|c|c|c|}
\hline Subíndices & $\begin{array}{l}\text { Variável para o caso de países } \\
\text { (GGGR 2018) }\end{array}$ & $\begin{array}{c}\text { Variável para o caso de unidades } \\
\text { federativas }\end{array}$ & Fonte de dados \\
\hline \multirow{4}{*}{$\begin{array}{l}\text { Participação } \\
\text { Econômica e } \\
\text { Oportunidade }\end{array}$} & $\begin{array}{c}\text { Proporção: força de trabalho } \\
\text { feminina sobre força de trabalho } \\
\text { masculina }\end{array}$ & $\begin{array}{l}\text { Proporção: mulheres de } 14 \text { anos ou } \\
\text { mais na incluídas na força de trabalho } \\
\text { sobre a contraparte masculina }\end{array}$ & $\begin{array}{c}\text { PNAD - } 2^{\mathrm{a}} \text { Trimestre de } \\
2018\end{array}$ \\
\hline & $\begin{array}{l}\text { Remuneração feminina em relação à } \\
\text { remuneração masculina para trabalhos } \\
\text { semelhantes (survey, escala de } 0 \text { a 1) }\end{array}$ & $\begin{array}{l}\text { Proporção: média do salário feminino } \\
\text { sobre a média do salário masculino }\end{array}$ & $\begin{array}{l}\text { PNAD - } 2^{\mathrm{a}} \text { Trimestre de } \\
2018 \text { - Rendimento médio } \\
\text { do trabalho principal }\end{array}$ \\
\hline & $\begin{array}{c}\text { Proporção: ganhos monetários } \\
\text { femininos sobre ganhos monetários } \\
\text { masculinos }\end{array}$ & $\begin{array}{l}\text { Proporção: rendimento médio } \\
\text { feminino de todos os trabalhos sobre } \\
\text { a contraparte masculina }\end{array}$ & $\begin{array}{c}\text { PNAD - } 2^{\circ} \text { Trimestre de } \\
2018\end{array}$ \\
\hline & $\begin{array}{l}\text { Proporção: legisladoras, oficiais } \\
\text { e gerentes mulheres sobre a } \\
\text { contrapartida masculina }\end{array}$ & $\begin{array}{l}\text { Proporção: mulheres em posição de } \\
\text { empregadoras ou que trabalham por } \\
\text { conta própria sobre a contrapartida } \\
\text { masculina }\end{array}$ & PNAD Contínua 2016 \\
\hline \multirow{5}{*}{$\begin{array}{l}\text { Empoderamento } \\
\text { Político }\end{array}$} & $\begin{array}{l}\text { Proporção: mulheres com vagas } \\
\text { no parlamento sobre homens } \\
\text { parlamentares }\end{array}$ & $\begin{array}{l}\text { Proporção: deputadas federais sobre } \\
\text { deputados federais }\end{array}$ & $\begin{array}{l}\text { Estatísticas eleitorais } \\
2018 \text { - TSE }\end{array}$ \\
\hline & & $\begin{array}{l}\text { Proporção: deputadas estaduais/ } \\
\text { distritais sobre deputados }\end{array}$ & $\begin{array}{l}\text { Estatísticas eleitorais } \\
2018 \text { - TSE }\end{array}$ \\
\hline & & $\begin{array}{c}\text { Proporção: senadoras federais sobre } \\
\text { senadores }\end{array}$ & $\begin{array}{l}\text { Estatísticas eleitorais } \\
2014 \text { e } 2018 \text { - TSE }\end{array}$ \\
\hline & - & $\begin{array}{c}\text { Presença de Secretaria dedicada à } \\
\text { questão de gênero }\end{array}$ & $\begin{array}{c}\text { Sites oficiais dos governos } \\
\text { estaduais }\end{array}$ \\
\hline & $\begin{array}{l}\text { Proporção: anos com mulheres como } \\
\text { chefes de Estado sobre anos com } \\
\text { homens na chefia de Estado (nos } \\
\text { últimos } 50 \text { anos) }\end{array}$ & $\begin{array}{l}\text { Proporção: anos com mulheres como } \\
\text { governadoras do estado sobre anos } \\
\text { com homens no governo (nos últimos } \\
50 \text { anos) }\end{array}$ & $\begin{array}{l}\text { Sites oficiais dos tribunais } \\
\text { eleitorais }\end{array}$ \\
\hline
\end{tabular}

Fonte: Elaborado pelos autores.

Para elaborar o ranking de paridade de gênero, foram seguidos os quatro passos do GGGR. O primeiro deles foi a coleta dos dados e sua transformação em proporções, exceto o caso da variável de presença de secretaria dedicada às mulheres, sendo essa transformação necessária para que as diferenças entre homens e mulheres fossem levadas em consideração, e não os valores absolutos. Depois, o truncamento das variáveis a um ponto de referência para igualdade geralmente definido como 1 , mas que foi de 0,944 no caso da taxa de natalidade feminina sobre a masculina, considerando que nascem mais indivíduos do sexo masculino, e 1,06 para o caso da expectativa de vida feminina sobre a masculina. Salienta-se que, nos casos em que o valor para mulheres foi maior do que o para homens (proporção maior que 1), o valor considerado foi 1, não tendo sido calculado um índice de paridade absoluta, que pune qualquer diferença entre os sexos, mas um que permite a observação de todos os pontos em que as mulheres são desfavorecidas e, consequentemente, exibe um caminho para que exista a paridade. Em terceiro lugar, realizou-se o cálculo dos subíndices por meio de uma média ponderada. Calculou-se o desvio padrão dos dados coletados e se dividiu esse valor por 0,01, de modo que os valores foram padronizados para refletir a variação, em termos de desvio padrão, que uma mudança de $1 \%$ acarretaria e considerar valores relativos em vez de absolutos. Esses valores, 
calculados de maneira preliminar, foram aplicados como pesos da média ponderada realizada para o cálculo dos pesos utilizados numa nova média ponderada que, finalmente, calcula o índice final, feito por meio de uma média aritmética dos quatro subíndices.

Após a elaboração do ranking de paridade de gênero das unidades federativas do Brasil, iniciou-se a segunda etapa da pesquisa, que consiste em investigar a atuação do órgão federal responsável pelas políticas para mulheres: a SPM, seu conselho e o CNDM. Nessa fase, coletaram-se dados secundários (documentos) e primários (entrevistas). Foram reunidos documentos ligados de maneira direta ou indireta à SPM e ao CNDM, como regimentos internos, estatutos, anais de conferências e atas de reuniões promovidas pelos órgãos. As entrevistas foram conduzidas, presencialmente ou por audioconferência, com conselheiras e ex-conselheiras do CNDM, entre abril e junho de 2018. Sete entrevistas foram realizadas, com base num roteiro de entrevista semiestruturado, totalizando 245 minutos e 59 segundos de áudio, o que implica uma duração média de 35 minutos.

As entrevistas gravadas e transcritas foram examinadas por meio da análise de conteúdo (Bardin, 2009), na qual se buscou classificar temas em comum levantados pelas respondentes em diferentes subcategorias, cada uma representando um grupo de observações semelhantes, sendo que as categorias principais foram oriundas das próprias perguntas elaboradas com base no referencial teórico. Aliada à análise documental, a de conteúdo fortaleceu a identificação dos stakeholders do CNDM e permitiu a aferição de mais detalhes para a classificação desses atores. Por fim, confrontaram-se as informações do ranking estadual de paridade de gênero, as linhas de ação do III PNPM e a análise de stakeholders do CNDM.

\section{RESULTADOS E DISCUSSÃO}

O GGGR confere um diagnóstico da situação das distinções entre gêneros em diferentes países, levando em conta os quatro subíndices apresentados. Na edição de 2018, o Brasil ficou em $95^{\circ}$ entre 149 países, uma posição abaixo da média, mesmo tendo conseguido, de acordo com o estudo, fechar as lacunas de saúde e sobrevivência e de grau de escolaridade. Tal posição indica um desempenho muito aquém do ideal nos demais subíndices. Em participação econômica e oportunidade, o país ficou na $92^{a}$ posição, com $64,5 \%$ da lacuna entre gêneros coberta, e em empoderamento político, ocupou a $112^{\text {a }}$ posição, com 10,1\% da diferença coberta. Melo (2011) aponta que, a despeito das outras dimensões, a participação política é a única em que não há indícios de melhora no GGGR de 2010 e que nesse tópico reside a maior disparidade de gênero no Brasil. Ainda é observada a maior lacuna na dimensão política na edição de 2018 e percebida uma estagnação na dimensão econômica. $\mathrm{Na}$ adaptação da metodologia do GGGR para o caso das unidades federativas brasileiras, tornou-se possível a comparação do resultado nacional com a realidade vivenciada em cada uma de suas partes.

Na Tabela 1 são exibidas as unidades federativas brasileiras organizadas de acordo com seus desempenhos no índice final de paridade entre os gêneros juntamente com o desempenho e a colocação em cada um dos quatro subíndices. Os três estados com a menor lacuna entre homens e mulheres, com base nos dados mais recentes disponíveis, foram Amapá, Distrito Federal e Maranhão, enquanto os três com a maior desigualdade foram Mato Grosso, Minas Gerais e Paraná. Um ponto em comum às três unidades federativas mais bem posicionadas no ranking e uma potencial explicação para esses resultados foi o desempenho acima da média nos subíndices de participação econômica e oportunidade e de empoderamento político, destacando-se o último por exibir as mesmas três unidades como as primeiras colocadas de seu ranking parcial, alavancadas pela presença de secretaria dedicada à questão de gênero em todas elas. 
RAP | Desigualdade de gênero nos estados brasileiros e análise dos stakeholders do Conselho Nacional dos Direitos da Mulher

\section{TABELA 1 RANKING FINAL E PARCIAL DA LACUNA DE GÊNERO NOS ESTADOS BRASILEIROS}

\begin{tabular}{|c|c|c|c|c|c|c|c|c|c|c|}
\hline \multirow[b]{2}{*}{ Estados } & \multicolumn{2}{|c|}{ İndice Final } & \multicolumn{2}{|c|}{$\begin{array}{c}\text { Saúde e } \\
\text { Sobrevivência }\end{array}$} & \multicolumn{2}{|c|}{$\begin{array}{c}\text { Grau de } \\
\text { Escolaridade }\end{array}$} & \multicolumn{2}{|c|}{$\begin{array}{l}\text { Participação } \\
\text { Econômica e } \\
\text { Oportunidade }\end{array}$} & \multicolumn{2}{|c|}{$\begin{array}{c}\text { Empoderamento } \\
\text { Político }\end{array}$} \\
\hline & Rank & Índice & Rank & Índice & Rank & Índice & Rank & Índice & Rank & Índice \\
\hline Amapá & 1 & 0,7375 & 27 & 0,9441 & 10 & 0,9535 & 2 & 0,7511 & 2 & 0,3012 \\
\hline Distrito Federal & 2 & 0,7346 & 9 & 0,9602 & 4 & 0,9606 & 7 & 0,7294 & 3 & 0,2881 \\
\hline Maranhão & 3 & 0,7283 & 26 & 0,9468 & 25 & 0,9268 & 11 & 0,7205 & 1 & 0,3190 \\
\hline Sergipe & 4 & 0,7201 & 16 & 0,9578 & 21 & 0,9410 & 1 & 0,7588 & 6 & 0,2227 \\
\hline $\begin{array}{l}\text { Rio Grande Do } \\
\text { Norte }\end{array}$ & 5 & 0,7187 & 19 & 0,9567 & 23 & 0,9355 & 15 & 0,7052 & 4 & 0,2775 \\
\hline Acre & 6 & 0,7151 & 10 & 0,9601 & 19 & 0,9413 & 16 & 0,7048 & 5 & 0,2543 \\
\hline $\begin{array}{l}\text { Mato Grosso Do } \\
\text { Sul }\end{array}$ & 7 & 0,7071 & 13 & 0,9596 & 17 & 0,9464 & 12 & 0,7133 & 7 & 0,2092 \\
\hline Roraima & 8 & 0,7062 & 12 & 0,9597 & 16 & 0,9466 & 3 & 0,7502 & 9 & 0,1683 \\
\hline $\begin{array}{l}\text { Rio Grande Do } \\
\text { Sul }\end{array}$ & 9 & 0,6991 & 14 & 0,9596 & 5 & 0,9583 & 19 & 0,7029 & 8 & 0,1757 \\
\hline Pernambuco & 10 & 0,6977 & 23 & 0,9534 & 15 & 0,9467 & 5 & 0,7386 & 10 & 0,1521 \\
\hline Rio De Janeiro & 11 & 0,6954 & 7 & 0,9606 & 13 & 0,9507 & 8 & 0,7287 & 14 & 0,1414 \\
\hline São Paulo & 12 & 0,6925 & 22 & 0,9547 & 6 & 0,9559 & 13 & 0,7124 & 11 & 0,1471 \\
\hline Amazonas & 13 & 0,6914 & 2 & 0,9642 & 2 & 0,9688 & 18 & 0,7032 & 17 & 0,1296 \\
\hline Paraíba & 14 & 0,6880 & 18 & 0,9568 & 26 & 0,9229 & 9 & 0,7263 & 12 & 0,1460 \\
\hline Alagoas & 15 & 0,6880 & 25 & 0,9508 & 14 & 0,9497 & 6 & 0,7323 & 20 & 0,1190 \\
\hline Bahia & 16 & 0,6855 & 24 & 0,9526 & 18 & 0,9460 & 14 & 0,7074 & 16 & 0,1358 \\
\hline Pará & 17 & 0,6841 & 21 & 0,9562 & 24 & 0,9334 & 17 & 0,7042 & 13 & 0,1427 \\
\hline Piauí & 18 & 0,6841 & 6 & 0,9608 & 27 & 0,9011 & 4 & 0,7489 & 18 & 0,1256 \\
\hline Espírito Santo & 19 & 0,6803 & 15 & 0,9580 & 11 & 0,9533 & 25 & 0,6737 & 15 & 0,1361 \\
\hline Tocantins & 20 & 0,6787 & 4 & 0,9617 & 22 & 0,9395 & 20 & 0,6926 & 19 & 0,1208 \\
\hline Goiás & 21 & 0,6733 & 5 & 0,9613 & 12 & 0,9510 & 23 & 0,6821 & 21 & 0,0988 \\
\hline Santa Catarina & 22 & 0,6724 & 11 & 0,9599 & 8 & 0,9549 & 21 & 0,6916 & 23 & 0,0834 \\
\hline Ceará & 23 & 0,6683 & 20 & 0,9567 & 20 & 0,9412 & 10 & 0,7232 & 27 & 0,0523 \\
\hline Rondônia & 24 & 0,6668 & 1 & 0,9643 & 3 & 0,9609 & 26 & 0,6438 & 22 & 0,0982 \\
\hline Paraná & 25 & 0,6635 & 17 & 0,9570 & 7 & 0,9551 & 22 & 0,6853 & 25 & 0,0564 \\
\hline Minas Gerais & 26 & 0,6630 & 8 & 0,9605 & 9 & 0,9536 & 24 & 0,6821 & 26 & 0,0560 \\
\hline Mato Grosso & 27 & 0,6628 & 3 & 0,9634 & 1 & 0,9718 & 27 & 0,6343 & 24 & 0,0817 \\
\hline
\end{tabular}

Fonte: Elaborada pelos autores. 
Os desempenhos das unidades federativas coincidem com os do país no sentido de serem positivos nas questões de saúde e educação, apesar de não apresentarem a paridade observada no trabalho original, e negativo no que se refere a economia e política. O movimento geral de bons resultados em saúde e educação faz com que esses subíndices percam peso no cálculo do índice geral, uma vez que apresentam pouca variação, ou seja, menor desvio padrão - por esse motivo, desempenhos positivos nas questões econômica e política têm grande impacto na classificação geral. A situação do Amapá ilustra esse ponto, uma vez que o estado ficou na última posição $\left(27^{a}\right)$ em saúde e sobrevivência e na $10^{\mathrm{a}} \mathrm{em}$ grau de escolaridade, mas obteve o primeiro lugar no ranking geral graças à $2^{\mathrm{a}}$ posição obtida nos dois subíndices restantes. Segundo Melo (2011), o resultado insatisfatório do Brasil em participação política feminina, em conjunto com a participação econômica, foi determinante para o mau desempenho do país no GGGR. Apesar de também apresentar diferenças sensíveis em saúde e educação entre os países mais bem colocados e os últimos do ranking internacional, a dimensão política, por apresentar as maiores variações, é a que teve o maior peso no resultado final do índice, assim como acontece neste trabalho. Percebe-se, portanto, uma fragilidade intrínseca no GGGR: a grande influência da dimensão sobre empoderamento político sobre o índice final.

A Figura 1 mostra todas as unidades federativas e todos os subíndices considerados, sendo a borda a representante da paridade de gênero e o centro do gráfico o representante da disparidade. Os resultados em saúde e educação foram melhores e com menos variação, enquanto os resultados em economia e política foram piores, principalmente nessa última, e mais variados.

\section{FIGURA $1 \quad$ UNIDADES FEDERATIVAS SEGUNDO SEUS DESEMPENHOS NOS SUBíNDICES}

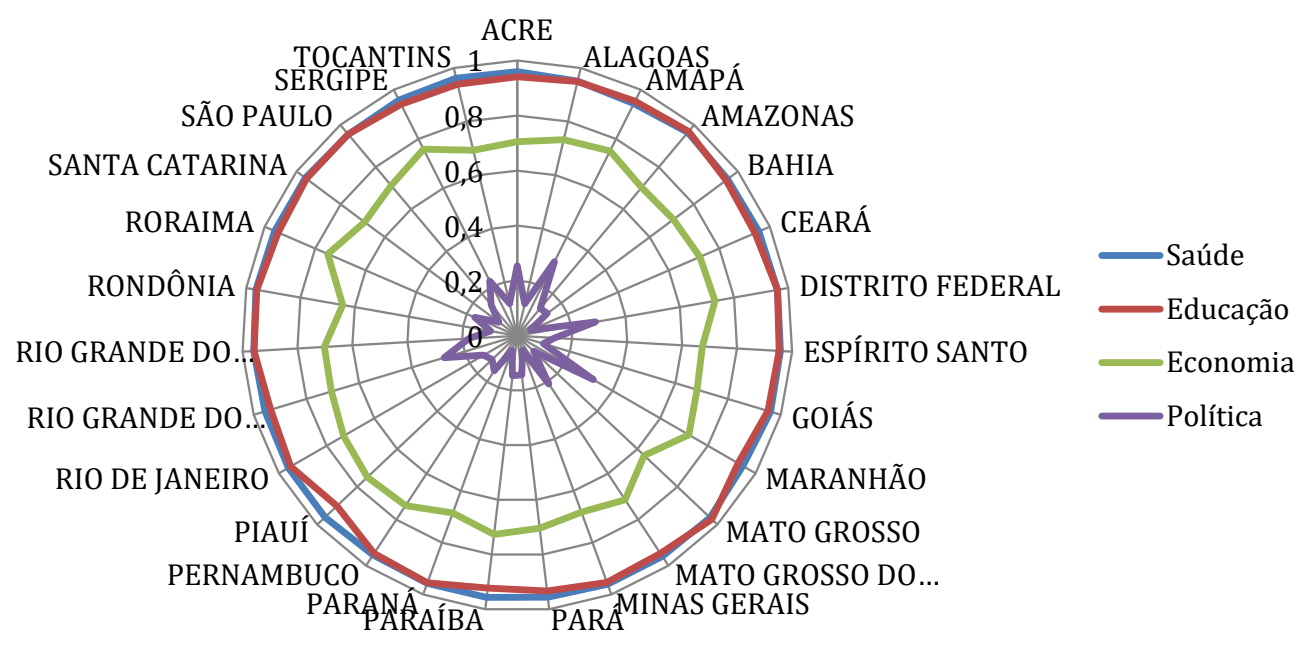

Fonte: Elaborada pelos autores. 
Ilustrando a semelhança entre os desempenhos no nível estadual e o desempenho nacional, a Figura 2 resume os resultados brasileiros no GGGR 2018, que conta com boas performances em saúde e educação, mas que ainda se encontram distantes do ideal em questões de política e economia.

\section{FIGURA 2 DESEMPENHO BRASILEIRO NO GGGR 2018}

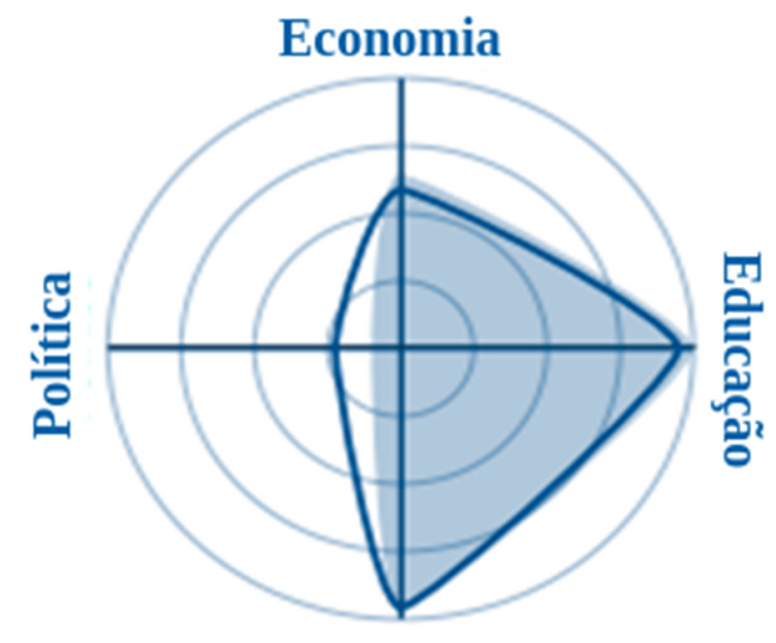

Saúde

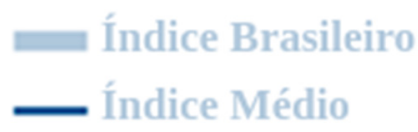

Fonte: WEF (2018).

Em 2019, alguns números demonstraram a disparidade entre homens e mulheres na política: 17 unidades federativas jamais tiveram uma mulher governadora; 18 estados não têm nenhuma representante feminina no Senado; e o Brasil é o $134^{\circ}$ colocado, entre 192 países, no mapeamento de representatividade feminina no legislativo nacional feito pela Inter-Parliamentary Union (2019), apesar de as cotas parlamentares estarem em vigência. O Maranhão, primeiro colocado no ranking de empoderamento político, tem um índice de apenas 0,3190 , ou seja, mesmo o melhor desempenho entre as unidades federativas é baixo.

Diante desse cenário, torna-se imprescindível a participação do governo para a redução e eventual eliminação da lacuna entre os gêneros, e essa participação se dá por meio das políticas públicas, que encontram seu principal local de discussão e fomento na SPM. Dentro da secretaria, o principal espaço de discussão dos problemas enfrentados pela população feminina é o CNDM - que tem uma estrutura que contempla com igualdade representantes da sociedade civil, trazendo esses atores para mais perto do centro de poder - os e representantes governamentais, sendo 41 conselheiras titulares, das quais 16 são representantes do Poder Público federal, 21 são representantes de entidades da sociedade civil, 3 são mulheres com notório conhecimento das questões de gênero e atuação na luta pela promoção e pela defesa dos direitos das mulheres e 1 é conselheira emérita. 
Contar com a participação da sociedade civil feminina organizada oferece mais chances para uma política de gênero eficaz, e o Conselho se mostra um local apropriado para esse tipo de representação (Fox \& Lawless, 2012). De acordo com a entrevistada 6, o CNDM “[...] sempre esteve à frente de organizar, debater, fazer comissões, impulsionar mesmo, para que a conferência aconteça de forma bem participativa, bem democrática”, referindo-se às conferências nacionais nas quais as diretrizes dos Planos Nacionais de Políticas para as Mulheres são definidas.

O plano nacional, elaborado com participação direta das partes interessadas do conselho, foi planejado para enfrentar as lacunas de gênero presentes no país. Dentro do III PNPM existem capítulos que englobam cada um dos quatro subíndices abordados no ranking, sendo essa relação definida da seguinte maneira: subíndice de saúde e sobrevivência e Capítulo 3: Saúde integral das mulheres, direitos sexuais e direitos reprodutivos; subíndice de grau de escolaridade e Capítulo 2: Educação para igualdade e cidadania; subíndice de participação econômica e oportunidade e Capítulo 1: Igualdade no mundo do trabalho e autonomia econômica; e subíndice de empoderamento político e Capítulo 5: Fortalecimento e participação das mulheres nos espaços de poder e decisão.

Considerando que o CNDM tem influência na construção do PNPM, estudar seus stakeholders pode indicar os caminhos para a elaboração de políticas públicas mais frutíferas e que estejam de acordo com o objetivo do órgão de eliminar a discriminação da mulher no Brasil, garantindo sua livre participação na política, na economia e na cultura.

O Quadro 2 apresenta os 50 stakeholders do CNDM, que podem ou não ser órgãos dos quais conselheiras fazem parte, mapeados e classificados pela análise de documentos e do conteúdo das entrevistas, de acordo com os estudos de Mitchell et al. (1997), Savage et al. (1991) e Gomes et al.(2010).

\section{QUADRO 2 CLASSIFICAÇÃO DOS STAKEHOLDERS DO CNDM}

\begin{tabular}{|c|c|c|c|}
\hline \multirow[b]{2}{*}{ Stakeholders } & \multicolumn{3}{|c|}{ Modelos de Classificação } \\
\hline & $\begin{array}{l}\text { Mitchel, Agle e } \\
\text { Wood (1997) }\end{array}$ & $\begin{array}{c}\text { Savage } \\
\text { et al (1991) }\end{array}$ & $\begin{array}{l}\text { Gomes, Liddle e } \\
\text { Gomes (2010) }\end{array}$ \\
\hline Governo federal & Definitivo & $\begin{array}{l}\text { Supportive } \\
\text { Stakeholder }\end{array}$ & Regulador \\
\hline Governos estaduais & Definitivo & $\begin{array}{l}\text { Mixed Blessing } \\
\text { Stakeholders }\end{array}$ & Regulador \\
\hline Governos municipais & Definitivo & $\begin{array}{c}\text { Mixed Blessing } \\
\text { Stakeholders }\end{array}$ & $\begin{array}{c}\text { Desenvolvedor de } \\
\text { Agenda }\end{array}$ \\
\hline Central Única dos Trabalhadores (CUT) & Definitivo & $\begin{array}{l}\text { Supportive } \\
\text { Stakeholder }\end{array}$ & Legitimador \\
\hline Sociedade civil & Definitivo & $\begin{array}{l}\text { Nonsupportive } \\
\text { Stakeholder }\end{array}$ & Legitimador \\
\hline SPM & Definitivo & $\begin{array}{l}\text { Supportive } \\
\text { Stakeholder }\end{array}$ & $\begin{array}{c}\text { Desenvolvedor de } \\
\text { Agenda }\end{array}$ \\
\hline
\end{tabular}




\begin{tabular}{|c|c|c|c|}
\hline \multirow[b]{2}{*}{ Stakeholders } & \multicolumn{3}{|c|}{ Modelos de Classificação } \\
\hline & $\begin{array}{l}\text { Mitchel, Agle e } \\
\text { Wood (1997) }\end{array}$ & $\begin{array}{l}\text { Savage } \\
\text { et al (1991) }\end{array}$ & $\begin{array}{l}\text { Gomes, Liddle e } \\
\text { Gomes (2010) }\end{array}$ \\
\hline Casa Civil da Presidência da República & Definitivo & $\begin{array}{l}\text { Supportive } \\
\text { Stakeholder }\end{array}$ & Regulador \\
\hline $\begin{array}{l}\text { Secretaria Especial de Agricultura Familiar e do } \\
\text { Desenvolvimento Agrário, Ministério da Educação, Ministério } \\
\text { da Saúde }\end{array}$ & Definitivo & $\begin{array}{l}\text { Supportive } \\
\text { Stakeholders }\end{array}$ & Colaborador \\
\hline $\begin{array}{l}\text { Secretaria Nacional de Direitos Humanos, Ministério do } \\
\text { Esporte, Ministério da Cultura, Ministério da Ciência, } \\
\text { Tecnologia, Inovações e Comunicações, Ministério do Meio } \\
\text { Ambiente, Ministério do Trabalho e Emprego }\end{array}$ & Dominante & $\begin{array}{l}\text { Supportive } \\
\text { Stakeholders }\end{array}$ & Colaborador \\
\hline Polícias civil, militar e secretarias de segurança dos estados & Dominante & $\begin{array}{l}\text { Mixed Blessing } \\
\text { Stakeholders }\end{array}$ & Colaborador \\
\hline Ministério da Justiça & Dominante & $\begin{array}{l}\text { Mixed Blessing } \\
\text { Stakeholder }\end{array}$ & Controlador \\
\hline $\begin{array}{l}\text { ONGS: ABL, AMB, AMNB, CMB, ANTRA, BPW Brasil, } \\
\text { FENATRAD, FNMN, FMM, LBL, MAMA, MMM, MMC, Parto } \\
\text { do Princípio, RMM, REF, RNFS, UBM, UMIAB, UNE, ONU } \\
\text { Mulheres, ABGLT, CONTI, ABMCJ, Femocratas }\end{array}$ & Dependente & $\begin{array}{l}\text { Supportive } \\
\text { Stakeholders }\end{array}$ & Legitimador \\
\hline $\begin{array}{l}\text { Secretaria Nacional de Políticas de Promoção da Igualdade } \\
\text { Racial }\end{array}$ & Dependente & $\begin{array}{l}\text { Supportive } \\
\text { Stakeholder }\end{array}$ & $\begin{array}{l}\text { Desenvolvedor de } \\
\text { Agenda }\end{array}$ \\
\hline Empresas privadas & Dormente & $\begin{array}{c}\text { Mixed Blessing } \\
\text { Stakeholders }\end{array}$ & Colaborador \\
\hline Entidades Laborais: CFP, CONTAG, CNTI, CTB, CNTE & Demandante & $\begin{array}{l}\text { Marginal } \\
\text { Stakeholders }\end{array}$ & Legitimador \\
\hline
\end{tabular}

Fonte: Elaborado pelos autores.

O conselho conta com 10 stakeholders classificados como "definitivos", aqueles que têm poder, legitimidade e urgência, sendo os atores com maior potencial para influenciar ou ser influenciados pelas ações do CNDM. Nessa categoria, encontram-se o governo em suas esferas federal, estadual e municipal, inclusive sendo representado pela Casa Civil da Presidência da República, pela Secretaria Especial de Agricultura Familiar e do Desenvolvimento Agrário, pelos Ministérios da Educação e da Saúde, além da sociedade civil.

Classificados como "dependentes", detentores de legitimidade e urgência, mas que não têm poder, se encontram 26 atores, o maior grupo entre os stakeholders mapeados. Esse grupo foi formado quase exclusivamente por entidades de representação feminina da sociedade civil, citadas pelas entrevistadas como fontes de pressão positiva para o pleno funcionamento do CNDM, e são entendidas como supportive stakeholders na classificação de Savage et al. (1991). Para a entrevistada 3, o conselho é um espaço que "congrega vários ministérios e representantes da sociedade civil, ou seja, é realmente um espaço de diálogo, de articulação e de conhecer quem toca a pauta". Para a respondente 2, "não 
se faz política pública sem a participação da sociedade civil”. As falas das entrevistadas reiteram a importância do CNDM para o desenvolvimento da pauta de gênero nas políticas públicas nacionais, em particular como um canal de inclusão da mulher, por meio das representações coletivas da sociedade civil, num centro decisório que tem um poder do qual tais entidades não gozam. Dessa maneira, as questões importantes para a mulher brasileira ganham força no governo e podem se tornar objeto de políticas públicas mais direcionadas e efetivas.

Cinco stakeholders, entidades de classe, aparecem como "demandantes", pois têm apenas urgência em suas demandas. As empresas privadas surgem como "dormentes", já que têm poder, mas não olham a questão de gênero com urgência e legitimidade, apenas observando a situação para que possam se adaptar a quaisquer mudanças na legislação.

"Dominantes" são aqueles com poder e legitimidade para agir, mas que não o fazem por não tratarem o assunto com urgência. Os oito atores dessa categoria, no caso do CNDM, são entidades públicas que acabaram não colocando em prática políticas de gênero, apesar de a transversalidade desse tipo de política estar clara em documentos como o III PNPM.

De acordo com Souza (2006), uma característica básica da política pública é o reconhecimento de um problema para que soluções comecem a ser procuradas, sendo que essas soluções precisam contornar barreiras da própria administração pública e da sociedade. No caso das políticas de gênero, alguns dos problemas que devem ser observados e combatidos pelos gestores públicos são a estrutura engessada da administração pública, a falta de financiamento e o conservadorismo da sociedade.

Tratando sobre o dia a dia do CNDM, a entrevistada 4 afirma que "o que atrapalha o funcionamento do conselho são mais questões burocráticas internas da Secretaria de Políticas para a Mulher", enquanto a entrevistada 3 diz que o dinheiro destinado à causa de gênero "é um orçamento ainda muito reduzido, comparado com outros ministérios ou inclusive com outros grupos em situação de vulnerabilidade". Tais barreiras, em conjunto com a falta de urgência ou poder dos stakeholders envolvidos, dificultam o avanço do Brasil rumo à igualdade entre os sexos. Sabe-se que esses são problemas cristalizados nas raízes da administração pública brasileira e de difícil solução, já que grandes reformas estruturais são complexas, dispendiosas e demoradas, logo o gestor precisa encontrar soluções criativas para usar o orçamento de maneira eficiente e simplificar os processos burocráticos na área que lhe compete. A entrevistada 6 responde que outro ponto de pressão negativa é "a sociedade, uma sociedade muito conservadora e machista", questão que talvez possa ser resolvida, de maneira gradual, com políticas direcionadas à conscientização sobre a importância das políticas públicas voltadas às mulheres e o crescimento da participação feminina em cargos importantes da esfera pública. Uma alternativa para o fortalecimento da questão de gênero como um todo no Brasil é o fortalecimento do CNDM, que, nas palavras da entrevistada 5, "representa [...] a congregação de forças políticas, das vozes das mulheres para manter acesas as pautas femininas, as pautas das mulheres para as políticas públicas e para a sociedade".

Como os resultados do ranking nacional de paridade de gênero se mostraram, de certa forma, uniformes em todas as unidades federativas do país, é possível que os pontos de pressão negativa presentes na administração pública federal e na sociedade sejam algumas das muitas barreiras enfrentadas para a promoção de uma política de paridade de gênero no nível estadual. A dimensão de participação política e oportunidade surge como o tópico em que houve mais variação entre as unidades federativas, o que sugere temas para investigações futuras sobre o assunto com vistas a reduzir a disparidade de gênero. 
Com essas informações, é possível afirmar que as políticas públicas de gênero voltadas à saúde e à educação surtiram efeito ou que a natureza desses dois pontos sugere uma melhor distribuição desses direitos fundamentais entre os sexos. Isso não significa que tais aspectos devam ser deixados de lado pela esfera pública, e sim que as políticas relacionadas podem adquirir um novo papel de manutenção da situação atual e de correção de eventuais falhas, enquanto as políticas direcionadas aos outros subíndices devem ser mais incisivas no sentido de incluir cada vez mais a mulher na economia e na política.

O Quadro 3 exibe a análise conjunta dos stakeholders do CNDM, das linhas de ação encontradas no III PNPM e dos subíndices considerados no cálculo do ranking nacional de paridade de gênero. O capítulo do plano nacional correspondente à questão da saúde tem mais do que o dobro da média de linhas de ação dos outros capítulos, o que significa que a saúde foi o ponto fundamental da última edição do PNPM. Felizmente, o Brasil tem conseguido oferecer à parcela feminina de sua população condições igualitárias de atendimento no que se refere à saúde, e é importante que políticas de gênero focadas na saúde continuem a existir. Contudo, a priorização da saúde pode assumir um caráter mantenedor da situação atual, ao passo que as políticas relacionadas aos outros subíndices, com exceção da questão da educação, que também apresenta um bom nível nas unidades federativas e no país, carecem de políticas mais incisivas de combate à desigualdade e de inserção das mulheres em espaços importantes ainda frequentados por uma maioria masculina.

\section{QUADRO 3 ANÁLISE CONJUNTA DO III PNPM COM OS RESULTADOS DO RANKING E OS STAKEHOLDERS DO CNDM}

\begin{tabular}{l|c|l}
$\begin{array}{l}\text { Subíndice (ranqueamento de menor para maior } \\
\text { lacuna entre os gêneros) }\end{array}$ & $\begin{array}{c}\text { Linhas de } \\
\text { ação }\end{array}$ & $\begin{array}{c}\text { Entidades responsáveis } \\
\text { (classificação dos stakeholders) }\end{array}$ \\
$\begin{array}{l}\text { Saúde e Sobrevivência }\left(1^{\circ}\right) \\
\text { Grau de Escolaridade }\left(2^{\circ}\right)\end{array}$ & 6 & Ministério da Educação (Definitivo) e SPM (Definitivo) \\
\hline Participação Econômica da Saúde (Definitivo) e SPM (Definitivo)
\end{tabular}

Fonte: Elaborado pelos autores.

Em relação ao melhor desempenho nas dimensões de saúde e educação e desempenho inferior quanto à participação política e econômica, a homogeneidade nos resultados obtidos pelas unidades federativas no ranking de paridade de gênero pode ter raízes na aderência dos estados a programas nacionais, como o PNDM, que são centrados em saúde e educação em detrimento de outras políticas.

Outro ponto a ser destacado é a classificação dos stakeholders do CNDM que foram definidos no PNPM como colaboradores da SPM para a implementação das linhas de ação de cada capítulo. Para os fins deste trabalho, os atores com o maior número de aparições, entre os vários órgãos 
designados no PNPM, foram selecionados como entidade responsável. Enquanto o Ministério da Saúde (MS) e o Ministério da Educação (MEC) são classificados como stakeholders definitivos, o Ministério do Trabalho e do Emprego (MTE), extinto durante o governo de Jair Bolsonaro, foi classificado como dominante, e a Secretaria Nacional de Políticas de Promoção da Igualdade Racial (Seppir), como dependente. Stakeholders definitivos têm os atributos necessários para exercer plena influência, ao passo que os dominantes carecem de urgência e os dependentes, de poder para influenciar a política pública.

Por ser dominante, o MTE não trata do tema de gênero com urgência, o que pode ser interpretado como uma explicação para a desigualdade ainda marcante nos aspectos econômicos. Um exemplo da falta de urgência nesse ministério é o fato de o programa Pró-Equidade de Gênero e Raça, principal política pública desenhada com a intenção de reduzir a lacuna de gênero no mercado de trabalho (Pinto, Andrade \& Luz, 2009), ter sido criado em 2005 pela SPM, e não pelo MTE. Apesar de não deter a urgência necessária para alavancar a paridade entre os gêneros no setor econômico, o MTE também se classifica como supportive stakeholder e colaborador, já que contribui em alguns aspectos para o programa Pró-Equidade de Gênero. Como tem classificações favoráveis de acordo com os métodos de classificação de stakeholders além do de Mitchell et al. (1997), a intensificação das políticas já implementadas pelo MTE e da discussão sobre gênero nesse ministério são maneiras de torná-lo um ator definitivo, mais engajado com a igualdade entre mulheres e homens na economia.

A Seppir, principal aliada da SPM nas linhas de ação referentes ao empoderamento político das mulheres, foi classificada como um stakeholder dependente, com legitimidade e urgência em suas demandas, mas que carece do poder para buscá-las, o que dificulta as ações voltadas à redução da lacuna entre os gêneros na política brasileira, que tendem a ser ideias nunca colocadas em prática. A inclusão de cada vez mais mulheres na política nacional é uma forma de dar poder às políticas públicas de gênero, uma vez que a presença feminina em cargos de destaque na política age como um catalisador para políticas voltadas a mulheres (Desposato \& Norrander, 2008).

Entre as linhas de ação previstas no III PNPM, encontram-se projetos que envolvem diretamente o programa Pró-Equidade de Gênero e Raça e a Lei n 12.034/2019, ações governamentais voltadas à redução da desigualdade de gênero na economia e na política, áreas que apresentaram os piores desempenhos nas unidades federativas e no país como um todo. A linha de ação 1.1.4, do "Capítulo 1 - Igualdade no mundo do trabalho e autonomia econômica", busca "ampliar o Programa Pró-Equidade de Gênero e Raça e ações que visem à promoção das mulheres e alteração de dinâmicas de discriminação no local de trabalho" (SPM, 2013) e tem como principal órgão de apoio a Seppir, o que pode, pela ausência de poder desse stakeholder, explicar o baixo resultado dessa iniciativa e atestar a importância de gerir melhor as relações com esse ator. No caso da participação política, representada no III PNPM pelo "Capítulo 5 - Fortalecimento e participação das mulheres nos espaços de poder e decisão", a linha de ação que envolve a lei das cotas parlamentares para mulheres é a de número 5.4.1: "contribuir com o TSE para aplicação, fiscalização e monitoramento da Lei 12.034/2009" (SPM, 2013, p. 56), que não conta com stakeholders para ser alcançada, o que pode ser uma explicação para a ineficácia do projeto em todas as unidades federativas. 


\section{CONCLUSÕES}

Por meio do estudo conjunto do ranking de paridade de gênero nas unidades federativas brasileiras com a análise de stakeholders do Conselho Nacional dos Direitos da Mulher e das linhas de ação do III Plano Nacional de Políticas Públicas para as Mulheres, percebeu-se que o foco das políticas públicas de gênero no país está voltado para as áreas de saúde e educação, onde existem as menores lacunas entre homens e mulheres, enquanto a participação econômica e oportunidade, assim como empoderamento político, subíndices com pior desempenho no ranking dos estados e no GGGR, não recebem o mesmo tratamento. Além do menor número de linhas de ação do PNPM dedicadas aos subíndices menos desenvolvidos no Brasil, os stakeholders envolvidos na articulação das ações desses tópicos - Ministério do Trabalho e do Emprego, no caso da economia, e Secretaria Nacional de Políticas de Promoção da Igualdade Racial, na questão política - não são classificados como definitivos. O Ministério do Trabalho e do Emprego carece de urgência nas demandas de gênero, e a Secretaria Nacional de Políticas de Promoção da Igualdade Racial, de poder, enquanto os Ministérios da Saúde e da Educação têm poder, legitimidade e urgência para agir com maior impacto nas questões de gênero.

Saúde e sobrevivência e grau de escolaridade são subíndices importantes que devem continuar recebendo atenção e investimento. Contudo, para que a disparidade entre os gêneros no Brasil diminua, será necessário maior volume de políticas públicas direcionadas à participação econômica e oportunidade e ao empoderamento político das mulheres. Além de aumentar a quantidade de ações governamentais focadas na questão de gênero, necessita-se de cuidado com a qualidade desses projetos, tendo em vista os casos do Programa Pró-Equidade de Gênero e Raça e da Lei n 2.034/2009, voltadas respectivamente para a participação econômica e para a representatividade política das mulheres, que não cumpriram a totalidade de seus objetivos e carecem de revisões para alcançá-los.

Entre as unidades federativas brasileiras, aquelas que obtiveram as primeiras colocações (Amapá, Distrito Federal e Maranhão) se destacaram por ter melhor desempenho nas questões política e econômica, apesar de tais desempenhos estarem distantes da igualdade de gênero. As últimas colocadas (Mato Grosso, Minas Gerais e Paraná), por sua vez, figuraram entre as piores posições nesses dois quesitos. Uma limitação deste trabalho foi a ausência de uma análise aprofundada dos motivos que levam as unidades federativas a ocupar as primeiras ou as últimas posições do ranking, mas futuros estudos podem suprir esta lacuna.

Por fim, esta análise levantou uma série de questões que podem ser respondidas em trabalhos futuros, entre elas a investigação das melhores ou mais viáveis maneiras de fazer políticas públicas efetivas na redução da desigualdade entre os gêneros no Brasil, o estudo aprofundado dos motivos que levaram o Programa Pró-Equidade de Gênero e Raça e a Lei n 2.034/2009 a apresentar resultados aquém do esperado, a pesquisa sobre as limitações enfrentadas pelo MTE e pela Seppir para promover as dimensões de participação econômica e oportunidade e empoderamento político, a inclusão das categorias de Hardy (1996) para análise dos stakeholders do CNDM e o aperfeiçoamento do ranking de paridade de gênero das unidades federativas por meio da adição de novas variáveis ou novos subíndices, que levem em conta, por exemplo, questões de violência contra a mulher. 


\section{REFERÊNCIAS}

Anglade, B., Useche, P., \& Deere, C. D. (2017). Decomposing the gender wealth gap in Ecuador. World Development, 96, 19-31.

Bardin, L. (2009). Análise de conteúdo. Lisboa, Portugal: Edições 70.

Desposato, S., \& Norrander, B. (2008). The gender gap in Latin America: contextual and individual influences on gender and political participation. British Journal of Political Science, 39(1), 141-162.

Fox, R. L., \& Lawless, J. L. (2012). Entrando na arena? Gênero e a decisão de concorrer a um cargo eletivo. Revista Brasileira de Ciência Política, 8, 129-163.

Freeman, R. E. (1984). Strategic management: A stakeholder approach. Boston, MA: Pitman.

Gomes, R. C., Liddle, J., \& Gomes, L. O. M. (2010). A five-sided model of stakeholder influence. Public Management Review, 12(5), 701-724.

Hardy, C. (1996). Understanding power: bringing about strategic change. British Journal of Management, $7(1)$, S3-S16.

Instituto Brasileiro de Geografia e Estatística. (2018). Estatísticas de gênero: indicadores sociais das mulheres no Brasil. Brasília, DF: Autor.

Inter-Parliamentary Union. (2018). Women in national parliaments. Recuperado de https://data. ipu.org/women-ranking?month=9\&year=2019

Lei $n^{\circ} 7.353$, de 29 de agosto de 1985. (1985). Cria o Conselho Nacional dos Direitos da Mulher. Brasília, DF. Recuperado de http://www.planalto.gov.br/ ccivil_03/LEIS/1980-1988/L7353.htm

Lei $n^{\circ}$ 10.539, de 23 de setembro de 2002. (2002). Dispõe sobre a estruturação de órgãos, cria cargos em comissão no âmbito do Poder Executivo Federal, e dá outras providências. Brasília, DF. Recuperado de http://www.planalto.gov.br/ccivil_03/LEIS/2002/ L10539.htm

Lei $n^{\circ}$ 10.683, de 28 de maio de 2003. (2003). Dispõe sobre a organização da Presidência da República e dos Ministérios, e dá outras providências. Brasília, DF. Recuperado de http://www.planalto.gov.br/ ccivil_03/LEIS/2003/L10.683.htm
Lei $n^{\circ}$ 12.034, de 29 de setembro de 2009. (2009). Altera as Leis no 9.096, no 9.504 e no 4.737. Brasília, DF. Recuperado de http://www.planalto.gov.br/ ccivil_03/_Ato2007-2010/2009/Lei/L12034.htm

Lei $n^{\circ}$ 13.341, de 29 de setembro de 2016. (2016). Altera as Leis $n^{\circ} 10.683$ e $n^{\circ} 11.890$ e revoga a Medida Provisória no 717 . Brasília, DF. Recuperado de http://www.planalto.gov.br/ccivil_03/_Ato20152018/2016/Lei/L13341.htm

Macaulay, F. (2010). Trickling up, down, and sideways gender policy and political opportunity in Brazil. In. N. Lebon, \& E. Maier (Eds.), Women's activism in Latin America and the Caribbean: engendering social justice, democratizing citizenship (pp. 273-288). New Jersey, NJ: Rutgers University Press.

Medida provisória $n^{\circ}$ 696, de 2 de outubro de 2015. (2015). Extingue e transforma cargos públicos e altera a Lei $n^{\circ} 10.683$. Brasília, DF. Recuperado de http://www.planalto.gov.br/ccivil_03/_Ato20152018/2015/Mpv/mpv696.htm

Melo, H. P. (2011). Uma avaliação do desempenho brasileiro no Global Gender Gap Index do Fórum Econômico Mundial. Caderno Espaço Feminino, 24(2), 537-552.

Mitchell, R. K., Agle, B. R., \& Wood, D. J. (1997). Toward a theory of stakeholder identification and salience: defining the principle of the who and what really counts. Academy of Management Review, 22(4), 853-886.

Pinto, E. L., Andrade, H., Jr., \& Luz, R. P. (2009). Pró-equidade de gênero: incorporando políticas de ação afirmativa no mundo do trabalho. Revista do Serviço Público, 60(4), 401-413.

Rad, E. H., Bayazidi, Y., Delavari, S., \& Rezaei, S. (2016). Gender gap and inequality in health professionals' income in Iran. Medical Journal of Bakırköy, 12(2), 74-79.

Sampieri, R. H., Collado, C. F., \& Lucio, P. B. (2006). Metodologia da pesquisa. São Paulo, SP: McGraw-Hill.

Savage, G. T., Nix, T. W., Whitehead, C. J., \& Blair, J. D. (1991). Strategies for assessing and managing organizational stakeholders. Academy of Management Executive, 5(2), 61-75. 
RAP | Desigualdade de gênero nos estados brasileiros e análise dos stakeholders do Conselho Nacional dos Direitos da Mulher

Secretaria de Políticas para as Mulheres. (2013). Plano Nacional de Políticas para as Mulheres. Brasília, DF: Autor.

Souza, C. (2006). Políticas públicas: uma revisão da literatura. Sociologias, (16), 20-45.
United Nations Development Programme. (2019). Human Development Report 2019. New York, NY: Autor.

World Economic Forum. (2018). Global Gender Gap Report 2018. Geneva, Switzerland: Autor.

\section{Gabriel Oliveira Loiola Benigno}

https://orcid.org/0000-0003-1549-8326

Mestrando em Administração pela Universidade de Brasília (UnB). E-mail: loiolabenigno@gmail.com

\section{Diego Mota Vieira}

https://orcid.org/0000-0003-1275-1648

Doutor em Administração pela Universidade de Brasília (UnB); Professor do Programa de Pós-Graduação em Administração da Universidade de Brasília (UnB). E-mail: diegolmv@yahoo.com.br

\section{Jessica Eloísa de Oliveira}

\section{https://orcid.org/0000-0002-4549-6498}

Doutoranda do Programa de Pós-Graduação em Administração da Universidade de Brasília (UnB); Professora do Centro Universitário do Distrito Federal (UDF). E-mail: jessicaeloisa1@gmail.com 